\title{
ANÁLISIS ESTRUCTURAL DE LA CARNE DE JAMÓN DURANTE EL PROCESO DE COCCIÓN Y TEMPERATURA DE ALMACENAMI ENTO
}

\author{
STRUCTURAL ANALYSIS OF BEEF AND HAM DURI NG THE \\ COOKING PROCESS AND STORAGE TEMPERATURE
}

María González H¹*, M.Sc, Héctor Suárez M², Ph.D, Olga Martínez A³ , M.Sc.

\begin{abstract}
${ }^{1}$ Industria de Alimentos Zenú, Centro de Investigación y Desarrollo. Medellín, Colombia. 2Universidad Nacional de Colombia, Bogotá, Instituto de Ciencia y Tecnología de Alimentos ICTA. '3niversidad de Antioquia, Facultad de Química Farmacéutica. Medellín, Colombia. *Correspondencia: mgonzalezh@zenu.com.co
\end{abstract}

Recibido: Septiembre 15 de 2008; Aceptado: Agosto 10 de 2009.

\section{RESUMEN}

Objetivo. Determinar los cambios estructurales de jamón de cerdo por efecto del proceso de cocción y temperatura de almacenamiento. Materiales y métodos. Fueron realizados seis tratamientos, utilizando tres temperaturas internas de cocción $\left(72,75\right.$ y $\left.78^{\circ} \mathrm{C}\right)$ a una temperatura de almacenamiento de $4^{\circ} \mathrm{C}$. Un tratamiento definido como patrón absoluto, cocido hasta alcanzar una temperatura interna de $72^{\circ} \mathrm{C}$, sin tiempo de retención en cocción y un patrón relativo, elaborado bajo las mismas condiciones del patrón absoluto pero almacenado a $0^{\circ} \mathrm{C}$. En cada ensayo, fueron realizadas observaciones con microscopio óptico de luz sobre la estructura del tejido muscular y análisis instrumental de textura los días 0 , 26 y 42. Los datos obtenidos en este estudio fueron examinados mediante un análisis de varianza de una vía. Resultados. Los resultados reportaron que el jamón cocido a una temperatura de $75^{\circ} \mathrm{C}$ y tiempo de retención en cocción de 5 minutos, es más efectivo para disminuir el efecto negativo de la separación por pérdida de integridad estructural de las microfibrillas y de la estructura de la red de colágeno. El incremento en la dureza fue reportado para todos los tratamientos al final del periodo de almacenamiento. Conclusiones. El tratamiento que mejor comportamiento presentó a nivel microscópico fue el elaborado a $75^{\circ} \mathrm{C}$ como temperatura de cocción y 5 min de retención, donde las fibras de colágeno del tejido conectivo mantienen una arquitectura mas ordenada junto con la fibra muscular a lo largo del tiempo.

Palabras clave: Jamón, textura, colágeno. 


\section{ABSTRACT}

Objetive: To determine the structural changes on the pork ham by effect of the cooking process and the temperature of storing. Materials and methods. Six treatments were made, in those three internal temperatures were used $\left(72,75\right.$ and $\left.78^{\circ} \mathrm{C}\right)$, and one storing temperatures $4^{\circ} \mathrm{C}$. Additionally another treatment was done and called as "absolute treatment", cooked until it reached an internal temperature of $75^{\circ} \mathrm{C}$ without retain cooking time and with a storing temperature of $0^{\circ} \mathrm{C}$. In each treatment some changes were observed in the structure of the muscle tissue on the days 0,26 , and 42 . The observations were established by an optic microscope. The data obtained in this study was analyzed by analysis of variance of a single via test. Results. The results showed that the pork ham cooked at a temperature of $75^{\circ} \mathrm{C}$ and retain time of 5 minutes were more effective to diminish the negative effect of the separation and loss of the structural integrity on the myofibers and the structure of the collagen. Conclusions. The treatment improved performance presented at the microscopic was prepared at $75^{\circ} \mathrm{C}$ and 5 minutes of cooking restraint, where the collagen fibers of the connective tissue maintain a more orderly architecture along with the muscle fiber over time.

Key words: Ham, textura, collagen

\section{NTRODUCCI ÓN}

El jamón de cerdo es un producto cárnico procesado de gran popularidad en el mercado en Colombia, para el año 2007 presentó una producción aproximada de 6.872 toneladas (1). La calidad es influenciada por muchos factores, entre los que se considera el tecnológico, condiciones de almacenamiento, tipo de corte, composición de la salmuera inyectada, masajeo, tiempo y temperatura de cocción (2).

El músculo está conformado principalmente por fibras musculares, tejido conectivo y células grasas. Las proteínas, representan aproximadamente el $20 \%$ de la masa muscular y pueden dividirse en tres categorías en función de sus propiedades de solubilidad: proteínas sarcoplasmáticas 30-35\%, proteínas miofibrilares $50-55 \%$ y proteínas del estroma (proteínas del citoesqueleto y colágeno) $10-20 \%$ (3).

A nivel estructural, el músculo esquelético tiene una estructura compleja. Está cubierto por una capa de tejido conectivo, contiene el epimisio que recubre el músculo manteniendo unida la estructura interna, en la parte interna están ubicados una serie de pequeños haces de fibras (fascículos) rodeados por tejido conectivo denominado perimisio. Finalmente se encuentran las fibras musculares que son células individuales cubiertas por una capa de tejido conectivo llamada endomisio (4). Las miofibrillas son estructuras que cruzan las células del tejido muscular, están constituidas por la actina y miosina, responsables de las propiedades de contracción y elasticidad (5).

El colágeno es el principal constituyente del tejido conectivo intramuscular de la carne, ejerce una importante función en la textura final del producto y contribuye con su firmeza y dureza. Es desnaturalizado por medio del calentamiento, la primera consecuencia de ello es el acortamiento de las fibras. La temperatura a la cual es desnaturalizado el colágeno depende del contenido de prolina e hidroxiprolina: a mayor contenido, mayor es la temperatura necesaria. Durante la cocción de los alimentos, parte del colágeno es solubilizado y forma "gelatina", que imparte propiedades de viscosidad (4).

La temperatura y tiempo de cocción tienen un amplio efecto sobre las propiedades físicas de los productos cárnicos. Los componentes del músculo que afectan la textura del 
músculo son las proteínas miofibrilares y proteínas del tejido conectivo, colágeno y elastina. Durante el calentamiento las diferentes proteínas son desnaturalizadas, causando cambios estructurales en el jamón, como destrucción de membranas celulares, incremento de área entre fibras musculares, agregación y formación de gel miofibrilar de proteína miofibrilar y sarcoplasmática (6).

Es conocido que factores asociados a la calidad de jamones u otros productos cárnicos están estrechamente relacionados a la microestructura (7). En este sentido, los principales objetivos de estudios microestructurales ha sido encontrar evidencias del efecto de la textura relacionada con la retención de agua, sinéresis, y explicaciones sobre alteraciones durante la vida útil (8).

El objetivo del presente estudio fue describir el efecto de los diferentes tratamientos de cocción y refrigeración sobre la microestructura y textura del jamón de cerdo cocido durante el periodo de vida útil.

\section{MATERI ALES Y MÉTODOS}

Preparación del material experimental. Para cada ensayo, se sumergieron 25 bloques o moldes, conteniendo cada uno $10.7 \mathrm{~kg}$ en marmita de cocción con agua a $82^{\circ} \mathrm{C}$, hasta lograr una temperatura interna de los bloques de jamón de 72,75 y $78^{\circ} \mathrm{C}$ respectivamente, la cual se sostuvo durante 5 minutos para cada caso. Posteriormente el producto cocido fue enfriado hasta una temperatura de $4^{\circ} \mathrm{C}$ para realizar choque térmico, a continuación fue realizado el proceso de temple en cavas de almacenamiento con temperatura entre 2 y $4^{\circ} \mathrm{C}$, donde fueron mantenidos durante 48 horas. Finalmente fue tajado y empacado al vacío en unidades de 230 gramos, utilizando un empaque constituido por dos películas, la superior impresa, abre fácil, laminada con alta barrera a los gases, permeabilidad al oxígeno a $23^{\circ} \mathrm{C}$ y $0 \%$ de humedad relativa de $5 \mathrm{~cm}^{2} /$ día, permeabilidad al vapor de agua a $38^{\circ} \mathrm{C}$ y $90 \%$ de humedad relativa de $8 \mathrm{gm}^{2} /$ día; la inferior con las siguientes especificaciones, espesor de $90 \mu$, coextruida, alta barrera a los gases, permeabilidad al oxígeno a $23^{\circ} \mathrm{C}$ y $0 \%$ de humedad relativa de $3 \mathrm{~cm}^{2} /$ día, permeabilidad al vapor de agua a $38^{\circ} \mathrm{C}$ y $90 \%$ de humedad relativa de $6 \mathrm{gm}^{2} /$ día; en salas con condiciones de temperatura, humedad relativa y velocidad de aire controladas.

En la tabla 1 se presenta la codificación empleada para los diferentes tratamientos evaluados.

Tabla 1. Tratamientos de cocción y tiempo de retención en jamón de cerdo.

\begin{tabular}{ccc}
\hline Temperatura & $\begin{array}{c}\text { Tiempo de } \\
\text { retención }\end{array}$ & $\begin{array}{c}\text { No de } \\
\text { tratamiento }\end{array}$ \\
\hline $75^{\circ} \mathrm{C}$ de cocción & 5 min & 2 \\
$78^{\circ} \mathrm{C}$ de cocción & $\begin{array}{c}5 \mathrm{~min} \\
5 \text { min patrón } \\
\text { absoluto } \\
\text { (fresco) }\end{array}$ & 3 \\
$72^{\circ} \mathrm{C}$ de cocción & 4 \\
$72^{\circ} \mathrm{C}$ de cocción & $\begin{array}{c}5 \text { min } \\
\text { min patrón } \\
\text { relativo }\end{array}$ & 1 \\
$72^{\circ} \mathrm{C}$ de cocción & 0 \\
\hline
\end{tabular}

Preparaciones y observaciones histológicas. Las observaciones histológicas fueron realizadas con microscopio de luz. Muestras de fibra muscular de jamón ( $2 \times 4 \times 7 \mathrm{~mm})$ fueron envasadas en solución de formalina buferada y procesadas mediante técnica de histología propuesta por Suárez et al (9). Las muestras fueron fijadas en solución de Bouin y embebidas en parafina. Cortes de $5 \mu \mathrm{m}$ fueron realizados usando un micrótomo (PR-50, Yamato Kohki, Urawa, Japan) a secciones de músculo embebido en bloque de parafina. Los cortes fueron montados en láminas portaobjetos y teñidos durante 5 min con naranja $\mathrm{G}$ ( $0.5 \mathrm{~g}$ de naranja $\mathrm{G}, 1$ $\mathrm{mL}$ ácido acético disuelto en $99 \mathrm{~mL}$ de agua destilada y filtrada). Las secciones fueron lavadas con agua destilada y teñidas durante 5 min con azul de metileno $(0.07 \mathrm{~g}$ de azul de metileno, $1 \mathrm{~mL}$ ácido acético disuelto en $99 \mathrm{~mL}$ de agua destilada y filtrada). Las muestras coloreadas fueron lavadas durante 5 min con agua buferada destilada (9)

Se tomaron fotografías de las fibras musculares con la ayuda de un microscopio (Carl Zeiss, Axioestar, Germany) con cámara 
fotográfica digital incorporada (Canon Power Shot G5, Japan), fueron realizadas mediciones con la ayuda de un analizador de imagen (Carl Zeiss AxioVisión 4, Germany) y caracterizada la arquitectura muscular teniendo en cuenta el área entre las fibras musculares. Las observaciones fueron realizadas utilizando un lente de 20X.

Determinación instrumental de la textura. Muestras de jamón fueron cortadas en cilindros de $20 \times 30 \mathrm{~mm}$ utilizando un cortador de acero inoxidable

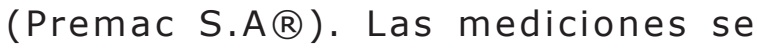
realizaron mediante un análisis de perfil de textura (TPA), usando un texturometro TA-XT2i (Stable Micro

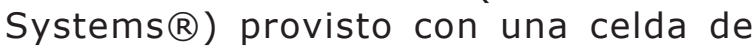
carga de $25 \mathrm{~kg}$ y una sonda de $20 \mathrm{~mm}$ de diámetro SMSP/20.(3,9,10). Las condiciones de operación fueron: velocidad de pre-ensayo $2 \mathrm{~mm} / \mathrm{s}$, velocidad de ensayo $10 \mathrm{~mm} / \mathrm{s}$, velocidad pos-ensayo $5 \mathrm{~mm} / \mathrm{s}$ y tiempo entre compresión de $1 \mathrm{seg}$. Las muestras de jamón fueron comprimidas uniaxialmente un $75 \%$ de la altura original en dirección perpendicular a las fibras musculares.

Análisis estadístico. Para el estudio del efecto de los tratamientos sobre la microestructura y textura, fue utilizada ANOVA de una vía sobre los resultados. La diferencia entre la media de los valores de los diferentes tratamientos fue determinada por el test de comparación múltiple de Duncan, y el nivel de significancia estadística definido fue de $(p<0.05)$.

\section{RESULTADOS}

El efecto sobre la microestructura del jamón durante el período de almacenamiento sobre los diferentes tratamientos, es observado en los cortes transversales de las fibras musculares en la figura 1 y 3 . Fue encontrada diferencia significativa $(p<0.05)$, entre los tratamientos respecto a la pérdida del tejido conectivo de las muestras observadas a nivel microscópico. La menor pérdida de área observada entre las fibras musculares fue presentada para el tratamiento $2\left(75^{\circ} \mathrm{C}\right)$ con tiempo de sostenimiento en cocción de 5 minutos (Tabla 2).

Las fibras de los jamones sometidos a los cuatro tratamientos durante el periodo de almacenamiento, mostraron un mayor espacio entre fibras y el tejido aparece fraccionado con pérdida del arreglo arquitectónico inicial.

La pérdida de la estructura arquitectónica en el jamón es debida a la contracción y desnaturalización de las fibras de colágeno, la cual, se presenta especialmente cuando el producto es sometido a procesos de calentamiento a $72{ }^{\circ} \mathrm{C}$ y posterior almacenamiento a $0^{\circ} \mathrm{C}$ (11). Donde fueron observados depósitos granulares en espacios entre el endomisio y la masa muscular. La presencia de gránulos indica el acortamiento pasivo de las fibras musculares, las cuales siguen estando unidas al azar por la red de fibras de colágeno. Para el tratamiento 0 fue observado que con el paso de los días las fibras de tejido conectivo se rasgan o se

Tabla 2. Área de separación de las fibras de colágeno de jamón de cerdo cocinado a diferentes temperaturas.

\begin{tabular}{cccc}
\hline $\begin{array}{c}\text { Temperatura de } \\
\text { cocción }\end{array}$ & $\begin{array}{c}\text { Temperatura y tiempo de } \\
\text { retención }\end{array}$ & $\begin{array}{c}\text { No. de } \\
\text { tratamiento }\end{array}$ & $\begin{array}{c}\text { Separación media } \\
(\boldsymbol{\mu} \mathbf{m})\end{array}$ \\
\hline $75^{\circ} \mathrm{C}$ de cocción & $4^{\circ} \mathrm{C}-5$ min & 2 & $5.90 \pm 0.40^{\circ}$ \\
$78^{\circ} \mathrm{C}$ de cocción & $4^{\circ} \mathrm{C}-5$ min & 3 & $6.51 \pm 0.40^{\circ}$ \\
$72^{\circ} \mathrm{C}$ de cocción & $4^{\circ} \mathrm{C}$ Omin patrón absoluto & 4 & $7.15 \pm 1.34^{\circ}$ \\
$72^{\circ} \mathrm{C}$ de cocción & $4^{\circ} \mathrm{C}-5$ min & 1 & $8.21 \pm 0.42^{\circ}$ \\
$72^{\circ} \mathrm{C}$ de cocción & $0^{\circ} \mathrm{C}$-0min patrón relativo & 0 & $14.49 \pm 0.64^{\circ}$ \\
\hline
\end{tabular}

Promedios con letras diferentes entre filas, son estadísticamente diferentes $(p<0.05)$, según la prueba rangos múltiples de Duncan. 


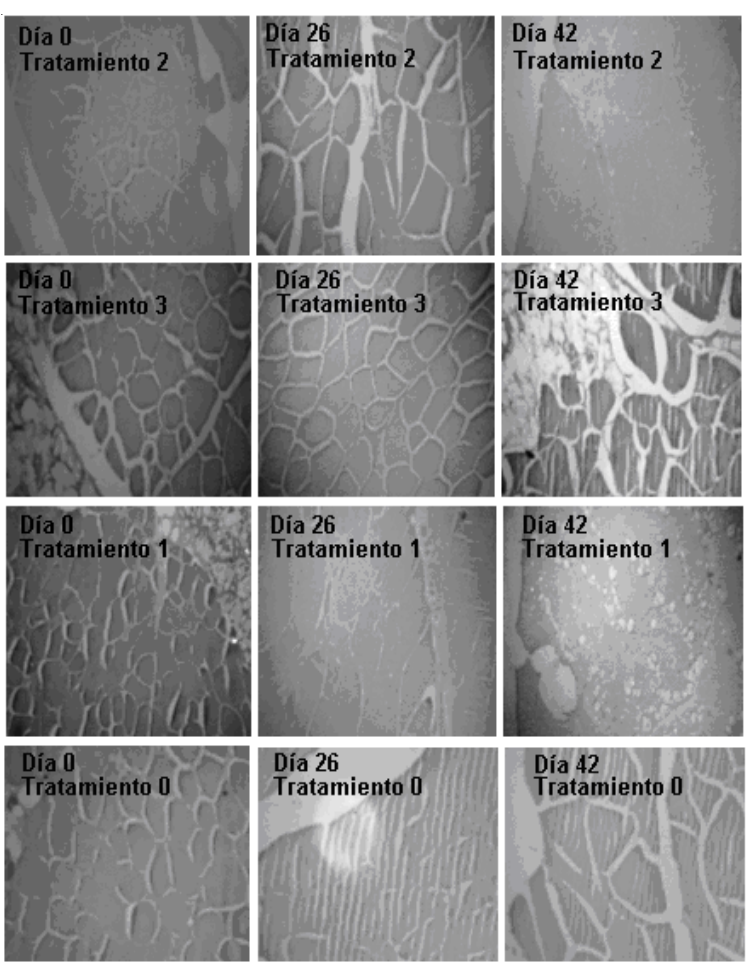

Figura 1. Microscopía óptica de cortes transversales de jamón cocido a $72^{\circ} \mathrm{C}$ de cocción - 0 min (tratamiento 0$) ; 72^{\circ} \mathrm{C}$ de cocción 5 min (tratamiento 1 ); $75^{\circ} \mathrm{C}$ de cocción - 5 min (tratamiento 2); $78^{\circ} \mathrm{C}$ de cocción - 5 min (tratamiento 3), en aumento 20x.

desintegran, evento que conlleva a una pérdida del arreglo arquitectónico con relación a la fibra muscular; además presentó espacios que muestran falla con el tejido conectivo del perimisio, mostrando granulado que proviene de la degradación de las células afectadas por la proteólisis y posterior deshidratación, especialmente al final del período de almacenamiento (Figura 1 y 3 ). Este fenómeno también se percibe en el tratamiento 3 pero solo al final del periodo de almacenamiento. El tratamiento 4 presentó un comportamiento intermedio en cuanto a la separación de las miofibrillas por degradación del colágeno durante el período de almacenamiento (Figura 2 y 3 ).

Para el tratamiento 2 se observa que la pérdida de tejido conectivo presenta los menores valores de separación. En contraste, el tratamiento 0 reporta las mayores áreas de separación entre miofibrillas, indicando
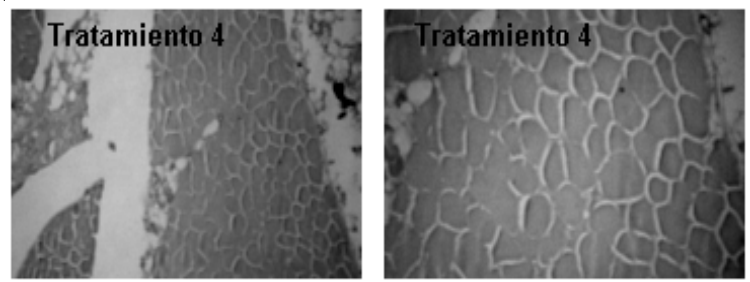

Figura 2. Microscopía óptica de cortes transversales de jamón cocido para el tratamiento 4 a $72^{\circ} \mathrm{C}$ de cocción y 5 min de retención en aumento 20x.

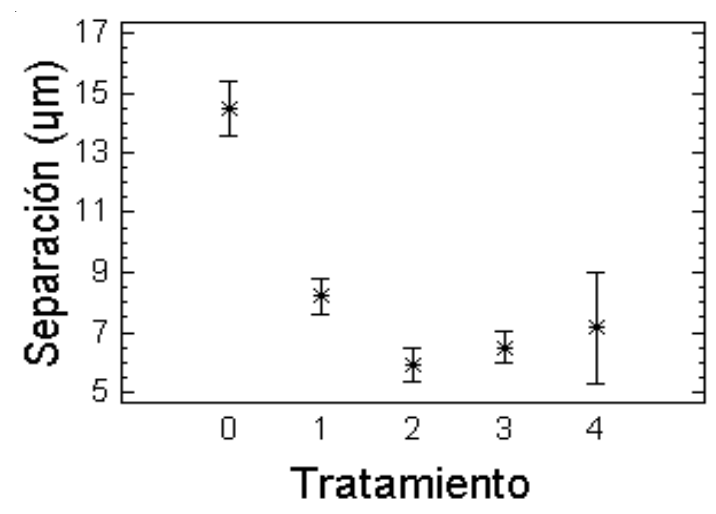

Figura 3. Separación del tejido conectivo $(\mu \mathrm{m})$ vs tratamiento.

degradación de las fibras de colágeno. Estas observaciones contrastan con el deterioro en la arquitectura muscular y refleja el mayor grado de ruptura del endomisio y perimisio.

En la tabla 3, se presentan los resultados de la separación entre las miofibrillas de jamón correspondientes al tratamiento 2 .

A lo largo del almacenamiento fue observado para el tratamiento $2\left(75^{\circ} \mathrm{C}\right.$ durante 5 min de retención y almacenado a $4^{\circ} \mathrm{C}$ ) que el área de separación entre las fibras musculares, para el día 34 de almacenamiento, fue menor frente

Tabla 3. Área de separación entre miofibrillas de jamón cocido a $75^{\circ} \mathrm{C}$ durante 5 min y almacenado a $4^{\circ} \mathrm{C}$.

\begin{tabular}{cc}
\hline \multicolumn{2}{c}{ Tratamiento 2} \\
\hline Tiempo (día) & Separación media $(\boldsymbol{\mu m})$ \\
\hline 0 & $4.59 \pm 0.64^{\circ}$ \\
14 & $4.65 \pm 0.64^{\circ}$ \\
34 & $5.48 \pm 0.64^{\circ}$ \\
42 & $6.77 \pm 0.64^{\circ}$ \\
26 & $7.99 \pm 0.64^{\circ}$ \\
\hline
\end{tabular}


a los otros tratamientos, indicando una menor pérdida o degradación de tejido conectivo (Figura 4). La degradación y pérdida de colágeno que es observado a través de la separación entre la fibra muscular, fue mayor en el tratamiento 0 . Para ambos tratamientos fue observado un incremento en el distanciamiento de las fibras musculares respecto al tiempo de almacenamiento. Este es manifiesto para el tratamiento 0 y 2 en el día 34 y 26 respectivamente, seguido de un posterior descenso en los valores de área de separación debido posiblemente al reblandecimiento y debilitamiento alrededor de las fibras de colágeno, produciendo adhesión entre las fibras musculares (Figura 4).

Análisis de textura. En la figura 5 se presentan los resultados del comportamiento de la dureza respecto al tiempo de almacenamiento. Se observó para los tratamientos 1, 2, 3, 4 un comportamiento similar para la prueba instrumental; estos tratamientos mostraron un incremento de la dureza al final del período de almacenamiento. El tratamiento 2 presentó los mayores valores de dureza, coincidiendo con el

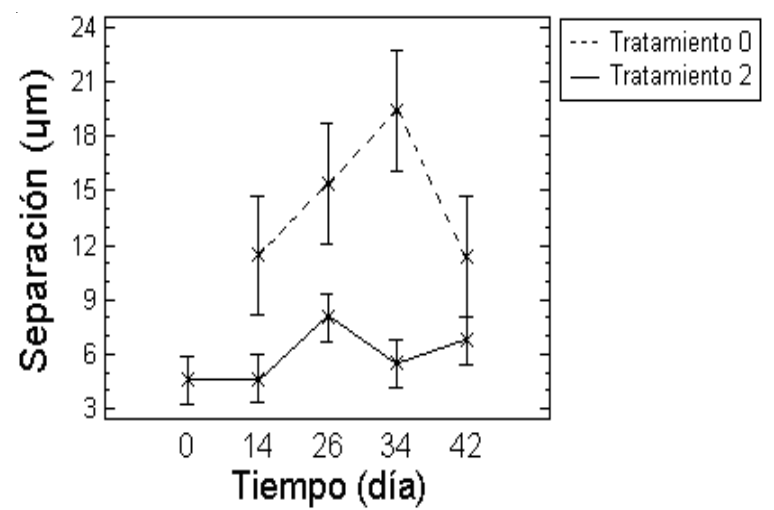

Figura 4. Área de separación entre miofibrillas de jamón cocido mediante dos tratamientos. Tratamiento $0: 72^{\circ} \mathrm{C}$ de cocción durante 0 min y almacenado a $0^{\circ} \mathrm{C}$ patrón relativo. Tratamiento 2 : $75^{\circ} \mathrm{C}$ de cocción durante 5 min y almacenado a $4^{\circ} \mathrm{C}$.

mantenimiento de la estructura arquitectónica observada en los análisis microscópicos. Los valores más altos de dureza fueron observados en el tratamiento 0 donde aparecen daños estructurales en las miofibrillas y tejido conectivo por la excesiva pérdida de agua durante el tiempo de almacenamiento.
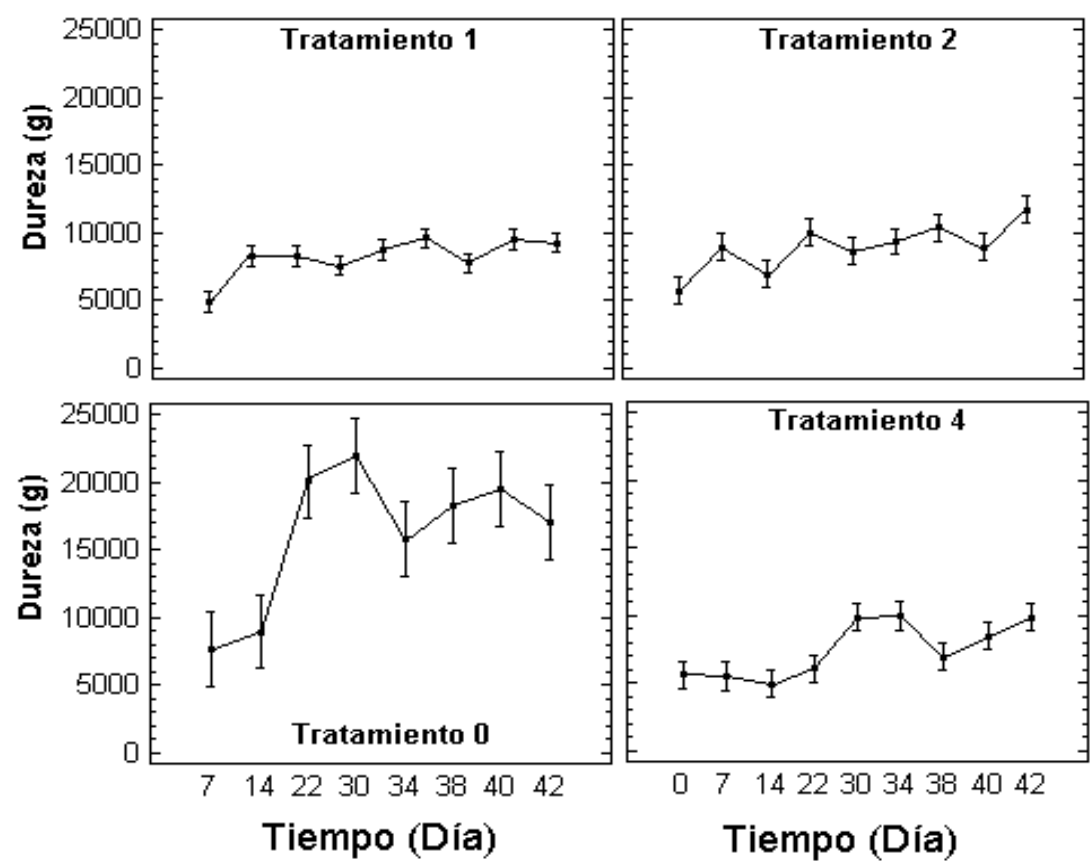

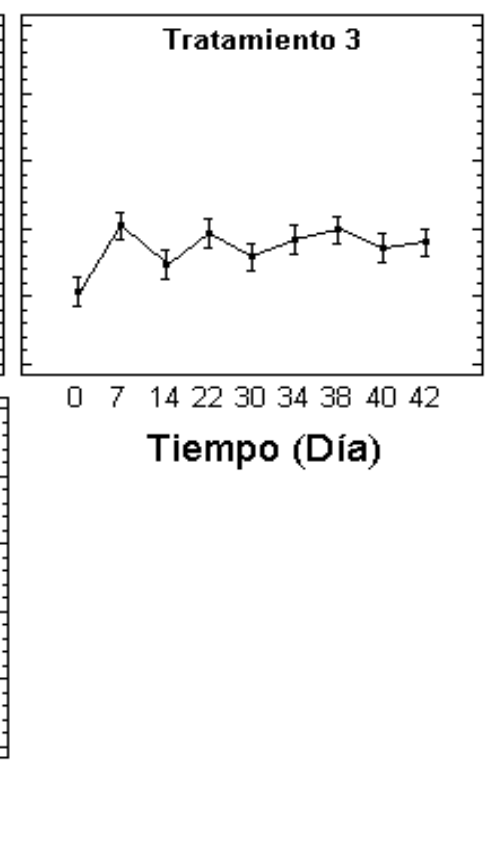

Figura 5. Dureza de jamón cocido. Tratamiento $0: 72^{\circ} \mathrm{C}-0 \mathrm{~min}-0^{\circ} \mathrm{C}$, Tratamiento $1: 72^{\circ} \mathrm{C}-5 \mathrm{~min}-4^{\circ} \mathrm{C}$ Tratamiento $2: 75^{\circ} \mathrm{C}-5 \mathrm{~min}-4^{\circ} \mathrm{C}$, Tratamiento $3: 78^{\circ} \mathrm{C}-5 \mathrm{~min}-4^{\circ} \mathrm{C}$, Tratamiento 4: $72^{\circ} \mathrm{C}-0 \mathrm{~min}$-fresco (patrón absoluto). 


\section{DISCUSIÓN}

Estudios realizados por Vasanthi et al (12) y Jones et al (13), reportan que la pérdida de la integridad estructural de las microfibrillas en el jamón cocido a temperaturas de 70 a $80^{\circ} \mathrm{C}$, es debido a la distorsión progresiva del endomisio y el perimisio, que dan lugar a deformación de la masa miofibrilar y conduce a la pérdida de la integridad estructural. Resultados similares fueron mostrados por Palka (14) quien encontró en músculos semitendinosos de bovinos cocinados en un rango de temperatura de 80 a $90^{\circ} \mathrm{C}$, cambios cualitativos en las fibras de colágeno con una marcada discontinuidad y distorsión del endomisio y el perimisio con el tiempo de almacenamiento, que indican una progresiva desnaturalización y pérdida de la integridad estructural. La figura 1 muestra cómo los espacios que originalmente estaban ocupados por tejido conectivo del perimisio, fueron posteriormente ocupados por sólidos procedentes de la proteólisis, especialmente al final del proceso.

Los cortes transversos de jamón cocido revelan un encogimiento pronunciado de fibras del músculo, generando mayores espacios entre fibras musculares, concordando con observaciones microscópicas realizadas por Kirchner et al (15). También claramente fue observado por Shaarani et al (16) el encogimiento por cocción inducido a nivel del espacio miofibrilar individual, al final del periodo de almacenamiento. El encogimiento del espacio miofibrilar probablemente es el resultado del calentamiento, que produce la desnaturalización de la proteína, afectando incluso proteínas como la titina, resultando en la exposición de áreas hidrófobas de la estructura miofibrilar, observándose como resultado, una estructura de la proteína más densa. Otros trabajos coinciden en afirmar que los cambios microestructurales, como la formación de huecos entre miofibrillas, ocurre mas frecuente durante el cocinado de productos cárnicos cocidos que de carnes frescas. Esto refleja que la desintegración de la fina estructura es más sensible al calor y afecta principalmente proteínas del colágeno y miofibrilar, alterando la integridad de la estructura nativa (17).
Por otra parte los cambios en la dureza durante la cocción pueden ser determinados por la rigidez mecánica del perimisio en el espacio endomisio-perimisio, mientras que el ablandamiento del endomisio supone pérdida de agua del músculo (14), ambos fenómenos contribuyen a la textura de la carne cocinada. Este fenómeno puede ser explicado por el grado de solubilización del colágeno y la formación de gel con pequeños grados de agregación (18), y producir ablandamiento del tejido conectivo con menor fuerza de penetrabilidad, producido por la desnaturalización de la miosina y proteínas sarcoplasmáticas relacionadas con la fuerza al corte. Como consecuencia de la actividad proteolítica generada durante el período de almacenamiento, la desintegración de las proteínas mifibrilares podría ocasionar un acortamiento de la estructura intracelular como es típico en este tipo de producto, donde las proteínas miofibrilares pueden ser responsables de la estructura final del jamón (7).

Los cambios en la dureza durante la cocción pueden ser afectados por la rigidez del perimisio y los espacios endomisio-perimisio, mientras que el acortamiento del endomisio supone pérdida de agua por parte del músculo (14), ambos fenómenos contribuyen con la textura de la carne cocinada. Sin embargo, en los tratamientos 1, 2, 3, 4 fue observado que las fibras de tejido conectivo del endomisio son más difusas y las miofibrillassarcoplasma no son compactas. Se considera que dichas diferencias pueden explicar la mayor solubilidad del colágeno y la formación de gel con menor grado de agregación en el tratamiento 0 , acorde con lo reportado por Tornberg (6). Además el almacenamiento a $0^{\circ} \mathrm{C}$, muestra como la unión de las miofibrillas al tejido conectivo es degradado, ocasionando debilitamiento de las conexiones de colágeno (15).

Por otra parte, durante el proceso térmico son generadas pérdidas de humedad, por ende un incremento en la dureza, este mismo resultado fue reportado por Goff (19), al evaluar los efectos de la calidad de jamones influenciada por métodos de cocción y almacenamiento. En tanto que otros autores $(20,21)$ en estudios sobre estabilidad de almidones en los alimentos, reportaron que 
la sinéresis presenta un incremento debido a fluctuaciones de temperatura que se generan durante el proceso de cocción del producto, por la insolubilización y precipitación espontánea de las moléculas de amilosa, ya que las cadenas lineales son orientadas paralelamente y accionan entre sí por puentes de hidrógeno, a través de múltiples enlaces hidroxilos, alterando las propiedades texturales del producto.

Las pruebas de textura a nivel instrumental mostraron incremento de los valores al final del período, coincidiendo con Flores et al (22), quienes observaron un aumento en la dureza instrumental a medida que transcurre el tiempo de almacenamiento de jamones madurados. Además, Lawrie y Ledward (4), encontraron que los diferentes tratamientos de cocción también pueden causar cambios en las propiedades de los productos cárnicos.

En conclusión, el tratamiento que mejor comportamiento presentó a nivel microscópico fue el elaborado a $75^{\circ} \mathrm{C}$ de cocción y 5 min de retención, donde las fibras de colágeno del tejido conectivo mantienen una arquitectura mas ordenada junto con la fibra muscular a lo largo del tiempo.

\section{REFERENCIAS}

1. Nielsen, Retail Measurement Services. Estudios de medición de mercados en Colombia. Diciembre-Enero 2008.

2. Delahunty M, Mccord A, O Neill E, Morrisey A. Sensory characterization of cooked hams by untrained consumers using free-choice profiling. Food Qual Prefer 1997; 8 (5-6):381-388.

3. Feiner G. Meat products handbook practical science and technology. Cambridge, England: Woodhead publishing limited; 2006.

4. Lawrie R, Lawrie's L. Meat science. The storage and preservation of meat: I Temperature control". Cambridge, England: Woodhead Publishing Itd; 2006.

5. Swatland $\mathrm{H}$. Stratification of toughness in beef roasts. Meat Sci 2007; 77:2-6.

6. Tornberg E. Effect of heat on meat proteins-Implications on structure and quality of meat products: A review. Meat Sci 2005; 70:493-508.

7. Larrea V, Perez M, Hernando I, Quiles A, Perez M. Changes in proteins during teruel dry cured ham processing. Meat Sci 2006; 74:586-593.
8. Aguilera J, Stanley D. Microestructural principles of food processing and engineering. Elsevier applied. J Food Sci 1999; 2:251-291

9. Suárez H, Pardo S, Beirao L, De Francisco A, Okada L. Efecto de la súper refrigeración sobre la textura de la carne de matrinxa (Brycon cephalus). Rev Colomb Cienc Pecu 2006; 19(2):221-227.

10. Lewis J, Purlow P. The strength and stiffness of perimysial connective tissue isolated from cooked beef muscle. Meat Sci 1989; 26:255-269.

11. Rowe D. Electron microscopy of bovine muscle: II the effects of heat denaturation of post rigor sarcolema and endomysium. Meat Sci 1989; 26:281-294.

12. Vasanthic C, Venkataramanujam V, Dushyanthan K. Effect of cooking temperature and time on the physicochemical histological and sensory properties of female carabeef (buffalo) meat. Meat Sci 2006; 76:274-279.

13. Jones B, Carroll J, Cavanaugh R. Structural changes in heated bovide muscle: a scanning electron microscope study. J Food Sci 1977; 42:125-131. 
14. Palka K. The influence of post mortem ageing and roasting on the microstructure, texture and collagen solubility of bovine Semitendinosus muscle. Meat Sci 2003; 64:191-198.

15. Kirchner $R$, Ofstad R, Skarpeid J, Host V, Kohler A. Monitoring of denaturation processes in aged beef loin by Fourier transform infrared microspectroscopy. J Agric Food Chem 2004; 52:3920-3929.

16. Shaaranis $S M$, Nott KP, Laurance DH. Combination of moisture and structure changes for convection cooking of fresh chicken meat. Meat Sci 2006; 72:398-403.

17. Bertram C, Kohler A, Bocker U, Ofstad $\mathrm{R}$, Andersen HJ. Heat-induced changes in myofibrillar protein structures and myowater of two pork qualities. A combined FT-IR spectroscopy and lowfield NMR relaxometry study. J Agric Food Chem 2006; 54:1740-1746.

18. Cheng Q, Sun Da-Wen. Quality of pork ham as affected by locations within sample Cooking methods and storage. J Food Procces Eng 2004; 65(4):551-556.
19. Goff D. Modified starches and the stability of frozen foods. Modified starches and the stability of frozen foods. In: "Starch in Food: Structure, Function and Applications." En: "El almidón en la alimentación: Estructura, Función y Aplicaciones". A.-C. Eliasson, ed. Eliasson, Woodhead Publishing, Cambridge, UK. Cambridge, Reino Unido: Woodhead Publishing; 2004: pp.425-440.

20. Guerra M, Cerero Y. Reseña sobre el uso de almidones y gomas en productos cárnicos. 2004; 221-226

21. Szcesniak A. Texture is a sensory property. Food Qual Prefer 2002; 13: 215-225.

22. Flores M, Casey C, Grimm C, Toldra F, Spanier A. Correlation of sensory and volatile compounds of Spanish ham as a function of two processing times. J Food Chem 1997; 45: 2178-2186. 